\title{
Short communication: Salt tolerance of Lactococcus lactis R-604 as influenced by mild stresses from ethanol, heat, hydrogen peroxide, and UV light
}

\author{
Ernesto E. Gonzalez, ${ }^{*}$ Douglas Olson, $\dagger$ and Kayanush Aryana $\dagger^{1}$ \\ *School of Animal Sciences, \\ †School of Nutrition and Food Science, Louisiana State University, Baton Rouge 70803
}

\begin{abstract}
Lactococcus lactis is a culture widely used in salt-containing dairy products. Salt hinders bacterial growth, but exposure to environmental stress may protect cells against subsequent stress, including salt. The objective of this study was to evaluate the salt tolerance of $L$. lactis R-604 after exposure to various stresses. The culture was subjected to $10 \%$ ( vol/vol) ethanol for 30 min, mild heat at $52^{\circ} \mathrm{C}$ for $30 \mathrm{~min}, 15 \mathrm{mM}$ hydrogen peroxide for $30 \mathrm{~min}$, or UV light $(254 \mathrm{~nm})$ for $5 \mathrm{~min}$ and compared with a control. Starting with 5 log cfu/ $\mathrm{mL}$ for all treatments, growth was determined in M17 broth with $5 \mathrm{NaCl}$ concentrations $(0,1,3,5$, and $7 \%$ wt/vol). Plating was conducted daily for $5 \mathrm{~d}$. Salt tolerance was enhanced with mild heat exposure before growth in M17 broth with 5\% (wt/vol) $\mathrm{NaCl}$ on d 3, 4 , and 5 , and with exposure to hydrogen peroxide and ethanol stresses before growth in M17 broth with 5\% (wt/vol) $\mathrm{NaCl}$ on d 4 and 5. Exposure of this culture to mild heat, hydrogen peroxide, or ethanol before growth in M17 broth containing 5\% (wt/vol) salt can enhance its survival, which could be beneficial when using it in salt-containing dairy products.
\end{abstract}

Key words: salt tolerance, Lactococcus lactis, cheese culture, cross-protection, bacterial growth

\section{Short Communication}

Previous exposure of Lactococcus lactis to low-intensity stress encourages resistance to the same stressors at lethal levels, because this first exposure initiates cell defense mechanisms (Hartke et al., 1994; Sanders et al., 1999). Exposure to an environmental stress can encourage resistance to different types of stressors because the many stress-induced proteins and low-molecular-weight compounds produced under more than one stress con-

Received September 30, 2016.

Accepted February 12, 2017.

${ }^{1}$ Corresponding author: karyana@agcenter.lsu.edu dition create an effect of cross-protection (Pichereau et al., 2000).

Ethanol is known to cause changes in the composition and function of bacterial cells, inhibit cell division, decrease viability and sugar transport systems, and affect the function of mitochondria and vacuoles. Exposure to $4 \%$ ( vol/vol) ethanol for $30 \mathrm{~min}$ confers heat resistance $\left(50^{\circ} \mathrm{C}\right.$ for $\left.25 \mathrm{~min}\right)$ to gram-positive bacteria such as Bacillus cereus by stimulating the production of heat-stress proteins such as GroEL, DnaK, and FtsH (Periago et al., 2002).

Heat is one of the most damaging stressors to bacteria. When most bacterial cells are under heat stress, they encode several proteins that act as chaperones to repair or destroy damaged structures (Yousef and Courtney, 2003). Some examples of heat-induced proteins are RecA, GroEL, grpE, DnaK, and hflB, which are involved in DNA repair and other protein synthesis (van de Guchte et al., 2002). These proteins are also associated with increasing resistance to oxidative stress, acidity, and cold temperature shock (Smith et al., 2010). Exposure to heat above the optimal growth temperature of microorganisms can activate resistance mechanisms that may increase their tolerance to other lethal stressors (Boutibonnes et al., 1991). Under osmotic stress with $2.5 \%$ (wt/vol) $\mathrm{NaCl}$, L. lactis produced heat-stress proteins such as DnaK, GroEL, and GroES. This overlap in protein production enhanced resistance to heat after a short osmotic shock (Kilstrup et al., 1997).

Oxidative stress can be defined as cells' response to an excessive accumulation of reactive oxygen compounds in the environment (Rochat et al., 2005); L. lactis and other lactic acid bacteria are very vulnerable to oxidative stress, because they lack the catalase activity to reduce hydrogen peroxide into water and oxygen (Rochat et al., 2005).

The viability of $L$. lactis can be reduced by almost $90 \%$ after $30 \mathrm{~min}$ exposure to $100 \mathrm{~kJ} / \mathrm{m}^{2} \mathrm{UV}$ light at $254 \mathrm{~nm}$, and stress-induced proteins such as GroEL and GroES are produced. Exposure of L. lactis to UV light 
increases its resistance to lethal challenges of other stresses such as acid, ethanol, heat, and hydrogen peroxide (Hartke et al., 1995). Pre-exposure to UV light encourages production of U1 protein, which protects the cell DNA from other stresses (Hartke et al., 1995). Similar to oxidative stress, UV light attacks the cell's DNA and is used as a mutagenic tool in several microorganisms (Miller, 1985). For gram-negative bacteria, 4 protection mechanisms have been proposed: RecA heat-induced protein synthesis to protect DNA; chemical modification of the cell membrane; permeability changes in the cell membrane; and reduction in cell division, which saves DNA for other uses. Some of these mechanisms may be used by L. lactis when it is exposed to UV light (Duwat et al., 1997).

One may question whether cultures widely used in salt-containing dairy products can become more resistant to one type of stress after previous application of another. For example, it is not known if the salt tolerance of L. lactis R-604 can be enhanced by previously subjecting it to other mild stress conditions. Our objective was to determine the effect of exposing L. lactis R-604 in M17 broth to different stressors (ethanol, mild heat, oxidative stress, and UV light) on its subsequent growth in M17 broth containing 0, 1, 3, 5, or 7\% (wt/ vol) $\mathrm{NaCl}$.

The conditions consisted of ethanol stress (30-min incubation in M17 broth at $30^{\circ} \mathrm{C}$ with $10 \% \mathrm{vol} / \mathrm{vol}$ ethanol), mild heat stress $\left(52^{\circ} \mathrm{C}\right.$ for $\left.30 \mathrm{~min}\right)$, oxidative stress (30-min incubation in M17 broth at $30^{\circ} \mathrm{C}$ with 15

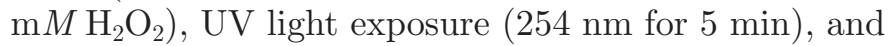
control (no stress). After each treatment, the culture was inoculated and incubated in M17 broth with 1 of 5 $\mathrm{NaCl}$ concentrations $(0,1,3,5$, and $7 \%$ wt/vol) without stirring for $5 \mathrm{~d}$. Bacterial counts were determined every $24 \mathrm{~h}$ for 5 consecutive days. Three replications of the experiments were conducted, and plate counts were performed in duplicate.

We used M17 broth for all samples and prepared it according to manufacturer specifications by diluting $37.25 \mathrm{~g}$ of M17 broth powder (Fisher Scientific, Fair Lawn, NJ) in $1 \mathrm{~L}$ of distilled water. This suspension $(94 \mathrm{~mL})$ was poured into dilution bottles and sterilized at $121^{\circ} \mathrm{C}$ for $15 \mathrm{~min}$. A $10 \%$ (wt/vol) lactose solution (Fisher Scientific) was prepared separately and sterilized under the same conditions. After autoclaving, 5 $\mathrm{mL}$ of the lactose solution was aseptically added to the sterile M17 bottles. The bottles were then tempered at $30^{\circ} \mathrm{C}$ in an aerobic incubator.

We used $1 \mathrm{~g}$ of pure L. lactis DVS culture R-604 (Chr. Hansen, Milwaukee, WI) for the control and the ethanol, mild heat, and oxidative stress treatments. The R-604 culture contained defined mesophilic strains of Lactococcus lactis without biovar diacetylactis (Chr.
Hansen, 2016). For the control, the culture was thawed and inoculated into $99 \mathrm{~mL}$ M17 broth supplemented with $0.5 \%$ (wt/vol) lactose without subjecting the culture to stress. The ethanol treatment consisted of thawing the culture and inoculating it into $99 \mathrm{~mL}$ M17 broth supplemented with $0.5 \%$ (wt/vol) lactose and $10 \%$ (vol/vol) ethanol before incubation at $30^{\circ} \mathrm{C}$ for $30 \mathrm{~min}$. The mild heat stress treatment consisted of thawing the culture and aseptically transferring it into $99 \mathrm{~mL}$ M17 broth supplemented with $0.5 \%$ (wt/vol) lactose before heating at $52^{\circ} \mathrm{C}$ for $30 \mathrm{~min}$ in a water bath and rapidly chilling in ice water. The oxidative stress treatment consisted of thawing the culture and inoculating it into $99 \mathrm{~mL}$ of M17 broth supplemented with $0.5 \%$ (wt/vol) lactose and $15 \mathrm{~m} M$ hydrogen peroxide before incubation at $30^{\circ} \mathrm{C}$ for $30 \mathrm{~min}$.

The UV light stress experiment was conducted according to Hartke et al. (1995) and Duwat et al. (1997) with some modifications. A $10-\mathrm{mL}$ sample of culture was aseptically poured into a sterile Petri dish and left uncovered $65 \mathrm{~cm}$ from the UV source (Germicidal 30W fluorescent tube; Sylvania, Wilmington, MA) at 254 $\mathrm{nm}$ for $5 \mathrm{~min}$ in laminar flow cabinet (Purifier class II; Labconco Corp., Kansas City, MO). Then, $1 \mathrm{~g}$ of this culture was inoculated into $99 \mathrm{~mL}$ of M17 broth supplemented with $0.5 \%$ (wt/vol) lactose.

After subjecting the cultures to each stress condition (ethanol, mild heat, oxidative stress, and UV light) or no stress, $1 \mathrm{~mL}$ of each sample was transferred to 5 different bottles containing sterile M17 broth with 0 , $1,3,5$, and $7 \%$ (wt/vol) $\mathrm{NaCl}$ (Fisher Scientific). The broths containing the cultures were immediately plated in M17 agar supplemented with $0.5 \%$ (wt/vol) lactose and incubated aerobically at $30^{\circ} \mathrm{C}$ (Kim et al., 2002) for $3 \mathrm{~d}$ before enumeration. The cultures in the M17 broths were incubated without stirring and drawn daily for $5 \mathrm{~d}$ for plating. All fluid samples and subsequent dilutions in dilution bottles were thoroughly shaken (American Public Health Association, 1992) before plating.

Data were analyzed as a completely randomized split-plot design with repeated measures over time using Proc Glimmix of SAS (version 9.3; SAS Institute Inc., Cary, NC). Significant differences were tested with least squares means at $P<0.05$ for main effects (stress conditions, time, and salt concentration), the interaction effect (stress conditions $\times$ salt concentrations $\times$ time of exposure), and paired comparisons.

Counts of L. lactis R-604 in M17 broth containing various salt concentrations over $5 \mathrm{~d}$ of salt exposure are presented in Table 1. However, these counts may have included potential lactococci chains in which each chain was counted as 1 colony. The 3 -way interaction between stress conditions $\times$ salt concentrations $\times$ days was significant $(P<0.05)$, meaning that $L$. lactis cell 
Table 1. Least squares means of cell counts (log cfu/mL) of Lactococcus lactis R-604 in M17 broth containing various salt concentrations to show its salt tolerance as influenced by exposure to stressors

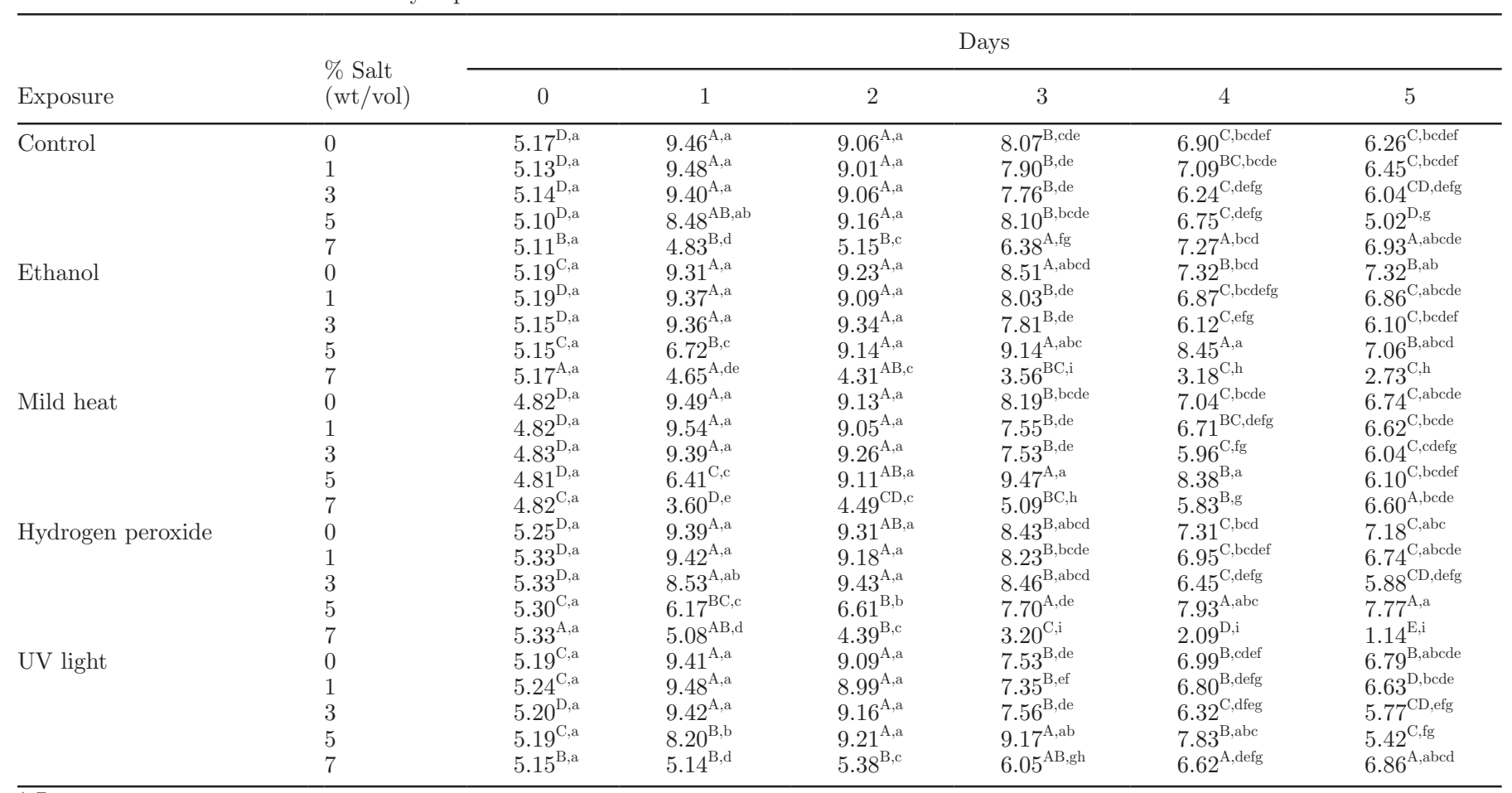

${ }^{\mathrm{A}-\mathrm{E}} \mathrm{LSM}$ without a common uppercase letter within a row were significantly different $(P<0.05)$.

${ }^{\mathrm{a}-\mathrm{i}} \mathrm{LSM}$ without a common lowercase letter within a column were significantly different $(P<0.05)$.

counts' dependence on the stress condition applied at a specific salt concentration over the days of exposure was not predictable.

Log counts for L. lactis were approximately $5 \mathrm{log}$ $\mathrm{cfu} / \mathrm{mL}$ immediately after inoculation into each broth for each salt concentration and were not significantly different from each other. For 0,1 , and $3 \%$ salt concentrations, the L. lactis counts usually increased by 4 to $5 \log$ units from d 0 to 1 , and these $\log$ counts showed a tendency to decrease progressively from d 1 to 5 . The log counts for the $5 \%$ salt concentration reached a peak between $\mathrm{d} 2$ and 4 before decreasing to $\mathrm{d} 5$. Variable trends for the effect of various stresses on $L$. lactis counts during storage occurred for the $7 \%$ salt concentration. The control did not show a consistent pattern during storage. Previous exposure to ethanol and hydrogen peroxide resulted in decreasing counts during storage. However, previous exposure to UV light and mild heat led to increasing counts after $1 \mathrm{~d}$ of storage. Although the 1 and $3 \%$ salt concentrations did not adversely affect $L$. lactis growth during storage compared with the control, the $5 \%$ salt concentration, and especially the $7 \%$ salt concentration, adversely affected its growth after $1 \mathrm{~d}$ of storage.

The effect of $\mathrm{NaCl}$ on L. lactis growth has been reported in other studies. Uguen et al. (1999) reported significant reduction $(70 \%)$ in the growth of L. lactis ADRIA 85L030 in $0.4 \mathrm{M} \mathrm{NaCl}$ and inhibition of growth at $0.5 \mathrm{M} \mathrm{NaCl}$ [equivalent to $3 \%$ (wt/vol) $\mathrm{NaCl}$ ] and higher. Obis et al. (2001) reported that several strains of L. lactis ssp. lactis and cremoris could grow at $6.5 \%$ (wt/vol) $\mathrm{NaCl}$, but for some other strains, growth was negatively affected at $2 \%(\mathrm{wt} / \mathrm{vol}) \mathrm{NaCl}$ and above. The difference in these results compared with our results could have been caused by the different strains used in each study.

The effects of ethanol, heat, oxidative stress, and UV light on growth and resulting changes have also been reported in other studies. According to van Bokhorstvan de Veen et al. (2011), ethanol pre-exposure can only confer cross-protection against heat stress because the damage that ethanol causes to the cell membrane mainly affects its permeability and fluidity, and it destabilizes enzymes on the membrane but increases the transcription of heat-stress-associated proteins. Exposure to heat $\left(39^{\circ} \mathrm{C}\right)$ can increase resistance to $\mathrm{NaCl}$, because heat-stress-induced proteins such as htrA are also used under osmotic stress as a defense mechanism (Foucaud-Scheunemann and Poquet, 2003). Kilstrup et al. (1997) showed that after $4 \mathrm{~h}$ of salt exposure [2.5\% (wt/vol) NaCl concentrations and higher], L. lactis growth was negatively affected. This study showed 
that several heat-stress genes, such as GroES, GroEL, and DnaK, can also be produced under osmotic stress. Desmond et al. (2002) showed that heat resistance can be achieved by previous sub-lethal exposure to salt [approximately $2 \%$ (wt/vol) $\mathrm{NaCl}$, because some genes produced under both stresses are the same. The lack of catalase activity in Lactococcus made it vulnerable to oxidative stress, which often leads to DNA and cell membrane damage that may weaken the bacterial cells and prevent them from growing in $7 \%$ (wt/vol) $\mathrm{NaCl}$ (Rochat et al., 2005). Hartke et al. (1995) showed that L. lactis exposed to $100 \mathrm{~J} / \mathrm{cm}^{2} \mathrm{UV}$ light can develop resistance to ethanol $(20 \% \mathrm{vol} / \mathrm{vol})$ and acid $(\mathrm{pH} 4.0)$ stress due to an overlap in stress-protein expression. In another study, Hartke et al. (1997) reported that $30 \mathrm{~min}$ of exposure to UV light at $254 \mathrm{~nm}$ was necessary to start the production of heat-stress proteins such as GroEL and GroES, which can also lead to a crossprotection effect.

Unlike the $\log$ counts of L. lactis R-604 grown in 1, 3 , and $7 \%$ salt concentrations, some of the log counts of cells grown in $5 \%$ salt concentration were significantly higher than $\log$ counts for the corresponding control. Specifically, log counts of L. lactis R-604 grown in 5\% salt and previously subjected to mild heat on $\mathrm{d} 3$, d 4 , and d 5 or to ethanol or hydrogen peroxide on d 4 and d 5 were significantly higher than the corresponding $\log$ counts of control L. lactis R-604 in 5\% salt. We can conclude that previous exposure to the stresses of ethanol, hydrogen peroxide, or mild heat before inoculation into M17 broth containing 5\% (wt/vol) salt provided resistance to $L$. lactis for enhancing subsequent growth after 3 or $4 \mathrm{~d}$ of storage.

\section{ACKNOWLEDGMENTS}

This study was funded by USDA Hatch funds and Louisiana State University Agricultural Center (Baton Rouge).

\section{REFERENCES}

Boutibonnes, P., B. Gillot, Y. Auffray, and B. Thammavongs. 1991. Heat shock induces thermotolerance and inhibition of lysis in a lysogenic strain of Lactococcus lactis. Int. J. Food Microbiol. 14:1-9.

Desmond, C., C. Stanton, G. F. Fitzgerald, K. Collins, and R. P. Ross. 2002. Environmental adaptation of probiotic lactobacilli towards improvement of performance during spray drying. Int. Dairy J. 12:183-190.

Duwat, P., A. Cochu, S. D. Ehrlich, and A. Gruss. 1997. Characterization of Lactococcus lactis UV-sensitive mutants obtained by ISS1 transposition. J. Bacteriol. 179:4473-4479.
Foucaud-Scheunemann, C., and I. Poquet. 2003. HtrA is a key factor in the response to specific stress conditions in Lactococcus lactis. FEMS Microbiol. Lett. 224:53-59.

Hartke, A., S. Bouche, X. Gansel, P. Boutibonnes, and Y. Auffray. 1994. Starvation-induced stress resistance in Lactococcus lactis ssp. lactis IL1403. Appl. Environ. Microbiol. 60:3474-3478.

Hartke, A., S. Bouche, J.-M. Laplace, A. Benachour, P. Boutibonnes, and Y. Auffray. 1995. UV-inducible proteins and UV-induced cross-protection against acid, ethanol, $\mathrm{H}_{2} \mathrm{O}_{2}$ or heat treatment in Lactococcus lactis ssp. lactis. Arch. Microbiol. 163:329-336.

Hartke, A., J. Frère, P. Boutibonnes, and Y. Auffray. 1997. Differential induction of the chaperonin GroEL and the co-chaperonin GroES by heat, acid, and UV-irradiation in Lactococcus lactis ssp. lactis. Curr. Microbiol. 34:23-26.

Kilstrup, M., S. Jacobsen, K. Hammer, and F. K. Vogensen. 1997. Induction of heat shock proteins DnaK, GroEL, and GroES by salt stress in Lactococcus lactis. Appl. Environ. Microbiol. 63:18261837.

Kim, W. S., J. H. Park, J. E. Tandianus, J. Ren, P. Su, and N. W. Dunn. 2002. A distinct physiological state of Lactococcus lactis cells that confers survival against a direct and prolonged exposure to severe stresses. FEMS Microbiol. Lett. 212:203-208.

Miller, J. H. 1985. Mutagenic specificity of ultraviolet light. J. Mol. Biol. 182:45-65.

Obis, D., A. Guillot, and M. Y. Mistou. 2001. Tolerance to high osmolality of Lactococcus lactis ssp. lactis and cremoris is related to the activity of a betaine transport system. FEMS Microbiol. Lett. 202:39-44.

Periago, P. M., W. van Schaik, T. Abee, and J. A. Wouters. 2002. Identification of proteins involved in the heat stress response of Bacillus cereus ATCC 14579. Appl. Environ. Microbiol. 68:34863495.

Pichereau, V., A. Hartke, and Y. Auffray. 2000. Starvation and osmotic stress induced multiresistances: Influence of extracellular compounds. Int. J. Food Microbiol. 55:19-25.

Chr. Hansen. 2016. R-604 Product Information. Version 4 PI EU EN 05-26-2016. Chr. Hansen, Hørsholm, Denmark.

Rochat, T., A. Miyoshi, J. Gratadoux, P. Duwat, S. Sourice, V. Azevedo, and P. Langella. 2005. High-level resistance to oxidative stress in Lactococcus lactis conferred by Bacillus subtilis catalase KatE. Microbiology 151:3011-3018.

Sanders, J. W., J. Kok, and G. Venema. 1999. Environmental stress responses in Lactococcus lactis. FEMS Microbiol. Rev. 23:483-501.

Smith, W. M., G. A. Dykes, A. H. Soomro, and M. S. Turner. 2010. Molecular mechanisms of stress resistance in Lactococcus lactis. Pages 1106-1118 in Current Research Technology and Education Topics in Applied Microbiology and Microbial Biotechnology. Vol. 2. Formatex, Badajoz, Spain.

American Public Health Association. 1992. Standard Methods for the Examination of Dairy Products. 16th ed. R. T. Marshall, ed. American Public Health Association, Washington DC.

Uguen, P., J. Hamelin, J.-P. Le Pennec, and C. Blanco. 1999. Influence of osmolarity and the presence of an osmoprotectant on Lactococcus lactis growth and bacteriocin production. Appl. Environ. Microbiol. 65:291-293.

van Bokhorst-van de Veen, H., T. Abee, M. Tempelaars, P. A. Bron, M. Kleerebezem, and M. L. Marco. 2011. Short-and long-term adaptation to ethanol stress and its cross-protective consequences in Lactobacillus plantarum. Appl. Environ. Microbiol. 77:5247-5256.

van de Guchte, M., P. Serror, C. Chervaux, T. Smokvina, S. D. Ehrlich, and E. Maguin. 2002. Stress responses in lactic acid bacteria. Antonie van Leeuwenhoek 82:187-216.

Yousef, A. E., and P. D. Courtney. 2003. Basics of stress adaptation and implications in new-generation foods. Pages 1-30 in Microbial Stress Adaptation and Food Safety. A. E. Yousef and V. K. Juneja, ed. CRC Press, Boca Raton, FL. 